\title{
Avaliação de Lâminas de Colpocitologia Oncótica Previamente Diagnosticadas como ASCUS: Comparação Interensaio e Interobservadores
}

\author{
Evaluation of Cervical Slides Previously Diagnosed as ASCUS: Interassay and \\ Interobserver Comparison
}

José Helvécio Kalil de Souza ${ }^{1,2}$, Ivana Vilela Kalil ${ }^{1,2}$, Juliana Moysés Leite ${ }^{1,2}$, Selmo Geber ${ }^{1}$

\section{RESUMO}

Objetivo: avaliar a existência de discordância intra e intercitopatologistas nas análises de lâminas de colpocitologias oncóticas que haviam recebido previamente o diagnóstico de células epidermóides atipicas de significado indeterminado (ASCUS) e o grau dessa discordância.

Métodos: estudo transversal no qual foram analisadas 50 lâminas de colpocitologias oncóticas coletadas no mês de novembro de 2000 no municipio de Contagem e com diagnóstico prévio de ASCUS. Elas foram analisadas e classificadas por quatro citopatologistas, de acordo com as alterações propostas na primeira revisão de Bethesda, em 1991 (normal, alteração atrófica, alteração inflamatória, sugestiva de lesão de baixo grau, sugestiva de lesão de alto grau, sugestiva de carcinoma invasor, outros). Após a primeira análise, as lâminas foram novamente numeradas, de maneira aleatória, e entregues aos mesmos citopatologistas para novo exame. Foi utilizado o teste de kappa e sua especificação pontual, o kappa ponderado, para análises dos resultados.

Resultados: observaram-se graus bastante distantes de concordância entre diferentes análises do mesmo citopatologista, variando de 7,8 a 74,4\%, (teste kappa). Quando foi instituido um peso para cada grau de discordância, os valores desse teste se elevaram, passando de 16,1\% para o citopatologista A a 81,08\% para o citopatologista $B$. Em relação às análises comparativas realizadas entre observadores distintos, os valores obtidos foram de $50,6 \%$ para o kappa e 63,4\% para a sua variação pontual.

Conclusões: a presente avaliação confirma a existência de subjetividade nos laudos citopatológicos de ASCUS, além de critérios imprecisos empregados pelo mesmo observador para obtenção desses resultados.

PALAVRAS-CHAVE: ASCUS. Colo do útero: lesões pré-neoplásicas. Colo do útero: câncer. Rastreamento para câncer. Citologia.

\footnotetext{
${ }^{1}$ Faculdade de Medicina da Universidade Federal de Minas Gerais, Belo Horizonte, Brasil

${ }^{2}$ Hospital Mater Dei, Belo Horizonte, Minas Gerais, Brasil Correspondência:

Juliana Moysés Leite

Av. Brasil 1653 - apto. 1101 - Funcionários

30140-002 - Belo Horizonte-MG

Telefone: (31) 3261-1030

Fax: (31) 3261-3013 - Cel: (31) 9114-6553

e-mail: julianambl@uol.com.br
}

\section{Introdução}

O câncer do colo uterino ainda hoje permanece como o segundo tumor maligno mais comum em mulheres, correspondendo a $15 \%$ de todos os cânceres femininos. Ele é considerado o de maior freqüência em vários países em desenvolvimento, nos quais corresponde a 20 a $30 \%$ do total dos tumores malignos em mulheres. Já nos países 
desenvolvidos do Ocidente, sua incidência é menor de $5 \%$ dos cânceres femininos ${ }^{1}$. Essa diferença reflete amplamente o impacto dos programas de rastreio de massa nos quais se utiliza o método da colpocitologia oncótica ${ }^{2}$.

Há muito se conhece o valor da colpocitologia oncótica como método eficaz para o rastreamento do câncer de colo. A classificação de Papanicolaou foi descrita no final da década de 20 e amplamente divulgada nos meados dos anos 40. Essa classificação apresenta, entretanto, algumas particularidades que não satisfazem plenamente os clínicos como, por exemplo, não apresentar correlação direta entre a sua classificação citológica e a conduta a ser instituída. Além disso, separa lesões com o mesmo potencial de evolução para o carcinoma invasor do colo em categorias distintas.

Diante disso, o Instituto Nacional do Câncer (National Cancer Institute - NCI), em 1988, patrocinou a criação de nova e atualizada terminologia a ser utilizada nos laudos da colpocitologia oncótica, a "Classificação de Bethesda", que visava a corrigir essas falhas existentes na classificação de Papanicolaou e a imprimir mais uniformidade aos laudos citológicos dos esfregaços do colo uterino. As recomendações surgidas passaram a ser chamadas de Sistema de Bethesda - TBS - The Bethesda System ${ }^{3}$.

Com o TBS foram introduzidos os termos citológicos de lesões intra-epiteliais escamosas de baixo grau (LoSIL) e lesões intra-epiteliais escamosas de alto-grau (HiSIL). As LoSIL compreendem os achados citopatológicos sugestivos de infecção pelo HPV e as neoplasias intra-epiteliais de grau leve (NIC I). Já as HiSIL incluem as neoplasias intra-epiteliais de grau moderado (NIC II) e de grau acentuado (NIC III). Embora essa nomenclatura não substitua os termos histológicos, os diagnósticos de LoSIL ou HiSIL apresentam correspondência com a possibilidade de progressão da patologia ${ }^{3}$.

Após alguns anos de ensaios clínicos, em 1991, o TBS foi revisto. Nessa nova classificação foi criada uma nova classe, a das ASCUS (atipias escamosas de significado indeterminado), que veio ocupar lacuna existente na antiga classificação de Papanicolaou, composta pelas alterações nas quais o citopatologista evidencia distorções citológicas, mais intensas do que as verificadas em alterações inflamatórias, sem, entretanto, preencher os critérios para sua classificação como displásicas ou neoplásicas. No TBS, as alterações reparativas e reativas são classificadas como dentro dos limites normais e, como alterações inflamatórias, somente aquelas que não estiverem relacionadas com a infecção pelo HPV (atipia coilocitótica). A categoria ASCUS inclui apenas esfregaços que têm a possibilidade de serem anormais, mas não podem ser classificados como reativos ou neoplásicos ${ }^{4}$. Essa categoria representa as limitações, à luz do microscópio, seguindo critérios precisos e uniformes para a doença prémaligna, em predizer a associação entre as aparências citológicas e a infecção pelo HPV, NIC e carcinoma invasivo do colo uterino. A categoria ASCUS representa, portanto, os achados citológicos que são de significância verdadeiramente indeterminada ${ }^{5}$.

A freqüência dos laudos de ASCUS após a análise do esfregaço é normalmente vista como indicador da qualidade dos exames de um laboratório. Com as normatizações recentes nos critérios diagnósticos, os resultados de ASCUS devem estar entre 3 e $5 \%$ do total dos esfregaços. Caso a porcentagem seja maior, deve-se pensar em excesso de diagnóstico das alterações reativas benignas, inflamatórias e reparativas, comumente secundárias à pressão médico-legal, resultando encaminhamentos desnecessários para exame colposcópico ${ }^{6}$.

Mesmo na presença de rigorosos critérios usados para o diagnóstico de ASCUS, o adequado manejo clínico diante desses resultados permanece controverso. Cerca de $70 \%$ das mulheres portadoras de esfregaço com diagnóstico de ASCUS não possuem lesão cervical visivel ao exame colposcópico ${ }^{7}$. Importante também é o fato de que 20 a $40 \%$ das pacientes com diagnóstico de ASCUS terão NIC associado, sendo que em 5 a $15 \%$ das vezes essa associação será com a lesão de alto grau ${ }^{8}$. Embora seja evento raro, o esfregaço com diagnóstico de ASCUS pode estar associado à presença de um câncer oculto em cerca de $0,1 \%$ das vezes ${ }^{9}$.

A recomendação clínica para o seguimento de paciente com diagnóstico colpocitológico de ASCUS é a repetição da colpocitologia em seis meses. A segurança nessa conduta é falha, pois, embora seja raro confundir achados citológicos de ASCUS com os de câncer invasor, a correspondência com HiSIL pode chegar a $15 \%$. Nesses casos, as possibilidades de a lesão evoluir para o carcinoma invasivo são bem maiores do que quando comparadas a todos os demais resultados possiveis, e essa espera pode alterar o prognóstico da paciente ${ }^{10}$.

Apesar dos avanços e das correções feitas no TBS, a categoria ASCUS permaneceu problemática para a prática dos patologistas. Vários autores passaram a demonstrar a fraca correlação entre as análises de diferentes observadores e a grande variação na freqüência nos diagnósticos de ASCUS, além de observarem que os achados de LoSIL não eram confirmados em grande parte das vezes em que as lâminas eram revisadas. 
De acordo com essas dificuldades, o NCI estabeleceu três frentes de tentativa de correção dessas distorções. Primeiramente, desenvolveu orientações provisórias para o acompanhamento e conduta em face de citologia cervical anormal. Em segundo lugar, organizou um grande estudo prospectivo, o ASCUS LoSIL Triage Study, a fim de determinar a melhor forma de conduzir esfregaços minimamente alterados. Por último, criou um atlas ilustrado contendo todas as categorias dessa classificação, bem como os critérios a serem avaliados para o diagnóstico citopatológico ${ }^{11}$.

No municipio de Contagem (MG) foi criado o programa de prevenção, diagnóstico e tratamento do câncer de colo e de seus precursores em novembro de 1999. Todas as citologias oncóticas coletadas no Sistema Único de Saúde (SUS) daquele município passaram a ser classificadas segundo a distribuição de Bethesda. Cerca de 10\% dos laudos, porém, estavam sendo diagnosticados como ASCUS, representando número superior à média encontrada em outras cidades de Minas Gerais e também do Brasil. Considerando essa divergência, tivemos como objetivo verificar se haveria, e qual seria, o grau de subjetividade no diagnóstico do item ASCUS dentro da classificação de Bethesda. Para isto a estratégia proposta foi de analisar comparativamente os laudos citológicos de lâminas previamente diagnosticadas como ASCUS, fornecidos por um mesmo citopatologista em duas observações distintas e analisar comparativamente os laudos citológicos de lâminas previamente diagnosticadas como ASCUS, fornecidos por quatro citopatologistas.

\section{Métodos}

Foi realizado estudo transversal do qual participaram as pacientes residentes no municipio de Contagem cujos exames preventivos do câncer do colo uterino foram coletados no SUS e tiveram seus resultados transferidos para o programa do Sistema de Avaliação das Patologias do Colo Uterino (SIS-Colo) do Ministério da Saúde. A classificação citológica utilizada, à época, era a do Sistema de Bethesda, do qual o diagnóstico de ASCUS faz parte.

O cálculo amostral prévio revelou a necessidade de análise de um mínimo de 36 lâminas distintas e a inclusão de número igual ou superior a três citopatologistas no presente estudo. Esse cálculo foi obtido contando-se a prevalência de $10 \%$ para o diagnóstico de ASCUS nessa amostra e por serem possiveis sete classificações formadas pelos citopatologistas participantes (normal, altera- ção atrófica, alteração inflamatória, sugestiva de lesão de baixo grau, sugestiva de lesão de alto grau, sugestiva de carcinoma invasor, outros). Todos os resultados foram considerados significativos em nível de $5 \%(\mathrm{p}<0,05)$, tendo, portanto, $95 \%$ de confiabilidade quanto à sua margem de erro. Foi utilizado o programa Epi-Info versão 6.04 b para a obtenção do cálculo amostral e a análise estatística foi feita pelos testes de kappa e sua especificação pontual (kappa ponderado).

Para a realização deste estudo, foram utilizadas lâminas provenientes dessas pacientes, obtidas no Laboratório Lux Vitae, que era o então responsável pela análise de todos os exames de colpocitologia oncótica na cidade de Contagem. O número inicial de lâminas incluídas nesta casuística foi de 2581, obtidas a partir dos exames colpocitológicos realizados no mês de novembro de 2000 naquele municipio. Desse total, 212 apresentavam diagnóstico de ASCUS, dado pela equipe de citotécnicos e citopatologistas do laboratório. Por fim, foi selecionado, de forma aleatória ${ }^{12}$, um total de 50 lâminas dentre essas últimas para a inclusão no acompanhamento. Todas essas lâminas foram numeradas progressivamente de um a 50 por dois acadêmicos de Medicina que auxiliaram na realização do estudo.

Todas as 50 pacientes incluídas a partir das lâminas selecionadas foram informadas e esclarecidas a respeito da pesquisa e colocadas livres para a não-aceitação da inclusão das lâminas de seus exames preventivos neste estudo. Todas aceitaram participar e assinaram documento de consentimento livre e esclarecido. A terapêutica instituída em todos os casos seguiria o protocolo do Serviço de Propedêutica, Prevenção e Tratamento das Patologias do Colo Uterino do Município de Contagem.

Foram utilizados os seguintes critérios de exclusão: coleta do material em local inadequado (ausência de células metaplásicas na lâmina), recusa da paciente a autorizar a inclusão da lâmina de seu exame no estudo e diagnóstico citológico mais para que de ASCUS.

As 50 lâminas foram entregues a cada um dos quatro citopatologistas participantes, de cada vez. Foram denominados de A, B, C, D, de forma aleatória, pelos acadêmicos participantes. Essa denominação não foi revelada ao autor até a conclusão total do estudo. Cada citopatologista recebeu um formulário para preenchimento conforme seus diagnósticos referentes a cada uma das lâminas (normal, alteração atrófica, alteração inflamatória, sugestiva de lesão de baixo grau, sugestiva de lesão de alto grau, sugestiva de carcinoma invasor, outros). Essa classificação faz parte das alterações sugeridas du- 
rante a primeira revisão do Sistema de Bethesda ocorrida também na cidade de Bethesda, em $1991^{5}$.

Os citopatologistas foram orientados a preencher cada laudo no espaço apropriado ao diagnóstico sugerido. Caso propusessem outro diagnóstico que não estivesse contido nos formulários, preenchiam o espaço reservado a "Outros", conforme orientação prévia, e descreviam, por extenso, o diagnóstico sugerido.

Após a primeira avaliação de todas as lâminas, realizada individualmente pelos quatro citopatologistas, elas foram renumeradas por outros dois acadêmicos participantes. Posteriormente, foram novamente entregues aos mesmos citopatologistas, a fim de que eles fizessem nova avaliação com o resultado sendo consignado em formulário idêntico ao da primeira. Após o término das análises feitas pelos quatro citopatologistas, estava disponivel para o estudo um total de 400 laudos citopatológicos compostos pelas duas avaliações realizadas em cada uma das 50 lâminas. Esses laudos foram, então, separados de forma a permitirem a realização das análises necessárias para responderem às questões pertinentes aos objetivos deste estudo. Os resultados obtidos na primeira avaliação, feita por citopatologista individualmente, foram comparados com os obtidos na segunda análise pelo mesmo profissional, para que fosse observado o grau de concordância de resultados obtidos em duas avaliações distintas feitas por um mesmo citopatologista. Também foram comparados os laudos das análises de cada um dos quatro citopatologistas. Essa etapa do estudo correspondeu a uma análise inter-observadores utilizando-se os dados obtidos nas séries de avaliações.

\section{Análise do grau de concordância}

A fim de que se quantificasse a magnitude das divergências entre os laudos colpocitológicos, foi feita nova análise levando-se em conta os graus de discordâncias. Isto pôde ser realizado adicionando-se pesos a cada grau de discordância, seguido por análise pelo método de kappa ponderado. Essa graduação de cada variação pode ser definida pelo autor, mas sempre respeitando o uso de valores idênticos a cada grau de discordância. Neste estudo, para cada grau de discordância encontrado foi considerado um valor de $20 \%$ como peso de variação.

\section{Resultados}

Não houve perda de material (lâminas estudadas) durante o estudo desta casuística. Do total de 400 avaliações, o ressecamento do material foi anotado em 11 dos laudos, sendo que não houve unanimidade em nenhuma das 50 lâminas estudadas em relação ao diagnóstico de ASCUS. Não houve confirmação de nenhum diagnóstico de ASCUS na revisão dos casos.

\section{Diagnósticos obtidos pelos observadores}

Foi identificada evidente predominância do laudo de alteração inflamatória sobre os demais nas duas análises feitas pelos observadores. Esse diagnóstico esteve presente em 45 e $51 \%$ das vezes na primeira e segunda análises, respectivamente (Tabela 1).

O diagnóstico de achados citopáticos que pudessem sugerir a presença de carcinoma invasor não estiveram presentes em nenhuma das análises realizadas e a freqüência de lesões sugestivas de alto grau (HiSIL) foi também bastante reduzida nessa amostra, sendo apresentada em $5,5 \%$ na primeira e $2,5 \%$ na segunda análise (Tabela 1).

Tabela 1 - Achados obtidos na primeira e segunda análises feitas individualmente pelos quatro observadores em 50 lâminas com diagnóstico prévio de ASCUS*.

\begin{tabular}{|c|c|c|c|c|c|c|c|c|c|c|c|c|c|c|c|c|}
\hline & \multicolumn{4}{|c|}{ A } & \multicolumn{4}{|c|}{ B } & \multicolumn{4}{|c|}{ C } & \multicolumn{4}{|c|}{ D } \\
\hline & \multicolumn{2}{|c|}{$1^{a}$ análise } & \multicolumn{2}{|c|}{$2^{\mathrm{a}}$ análise } & \multicolumn{2}{|c|}{$1^{\mathrm{a}}$ análise } & \multicolumn{2}{|c|}{$2^{\mathrm{a}}$ análise } & \multicolumn{2}{|c|}{$1^{a}$ análise } & \multicolumn{2}{|c|}{$2^{\mathrm{a}}$ análise } & \multicolumn{2}{|c|}{$1^{\mathrm{a}}$ análise } & \multicolumn{2}{|c|}{$2^{\mathrm{a}}$ análise } \\
\hline & $\mathrm{n}$ & $\%$ & $\mathrm{n}$ & $\%$ & $n$ & $\%$ & $\mathrm{n}$ & $\%$ & $\mathrm{n}$ & $\%$ & $n$ & $\%$ & $n$ & $\%$ & $\mathrm{n}$ & $\%$ \\
\hline Normal & 2 & 4 & - & - & 3 & 6 & 2 & 4 & 22 & 44 & 24 & 48 & 1 & 2 & 2 & 4 \\
\hline Atrófico & 3 & 6 & - & - & 1 & 2 & 2 & 4 & 5 & 10 & - & - & 3 & 6 & 1 & 2 \\
\hline Inflamatório & 32 & 64 & 34 & 68 & 26 & 52 & 26 & 52 & 6 & 12 & 10 & 20 & 26 & 52 & 32 & 64 \\
\hline Outros & 6 & 12 & 7 & 14 & 5 & 10 & 2 & 4 & 5 & 10 & 6 & 12 & 5 & 10 & 4 & 8 \\
\hline LoSIL & 1 & 2 & 2 & 4 & 14 & 28 & 17 & 34 & 12 & 24 & 8 & 16 & 11 & 22 & 9 & 18 \\
\hline HiSIL & 6 & 12 & 7 & 14 & 1 & 2 & 1 & 2 & - & - & 2 & 4 & 4 & 8 & 2 & 4 \\
\hline
\end{tabular}

* Células epidermóides atípicas de significado incerto.

A, B, C, D - Observadores.

$1^{\mathrm{a}}=1^{\mathrm{a}}$ análise. $2^{\mathrm{a}}=2^{\mathrm{a}}$ análise.

HiSIL - lesão intra-epitelial de alto grau.

LoSIL - lesão intra-epitelial de baixo grau.

-, Não houve achados compatíveis com carcinoma invasor. 
Os laudos citológicos fornecidos segundo cada um dos observadores em separado (Tabela 1) também deixaram claro que a predominância do diagnóstico de alteração inflamatória ocorreu nas duas análises feitas pelos quatro citopatologistas participantes. Pôde-se perceber, também, que a única unanimidade se fez quanto à ausência de suspeita de diagnóstico de neoplasia maligna invasora.

\section{Comparação interobservadores}

A comparação entre os laudos obtidos na primeira e na segunda análises dos quatro citopatologistas revelou que as maiores concordâncias ocorreram quanto aos diagnósticos de alterações inflamatórias, achados normais e de lesões de baixo grau (LoSIL), excetuando-se, como já referido anteriormente, a unanimidade encontrada quanto à ausência de diagnósticos sugestivos de lesões malignas invasoras.

O cálculo da avaliação de concordância de kappa revelou o valor de concordância de 50,6\%. Seguindo o propósito de avaliação do grau das discordâncias encontradas, foi realizada nova análise comparativa, na qual foi dado peso de 0,2 para cada categoria de discordância (Tabela 2) e foi realizado outro cálculo da variante da concordância de kappa, o kappa ponderado.

Tabela 2 - Avaliação comparativa inter-observadora das duas análises feitas, instituindose peso de $20 \%$ para cada grau de variação encontrado.

Normal Atrófico Inflamatório Outros LoSIL HiSIL Invasor

\begin{tabular}{lcllllll}
\hline Normal & 19 & 0,8 & 3,6 & 0,8 & - & - & - \\
Atrófico & 2,4 & 3 & 3,2 & 1,2 & - & - & - \\
Inflamatório & 1,8 & 0,8 & 72 & 4 & 5,4 & - & - \\
Outros & 0,8 & - & 2,4 & 9 & 3,2 & 1,8 & - \\
LoSIL & 0,2 & - & 6 & 0,8 & 26 & - & - \\
HiSIL & - & - & 2,8 & - & 1,6 & 2 & - \\
\hline
\end{tabular}

kappa - 0,634078

HiSIL - lesão intra-epitelial de alto grau.

LoSIL - lesão intra-epitelial de baixo grau.

-, Não houve achados de carcinoma invasor.

\section{Comparação entre os diagnósticos do mes- mo observador}

As análises das duas avaliações de cada observador são comentadas a seguir. Para cada um dos quatro observadores foi formulada uma tabela confrontando-se os resultados fornecidos nas duas análises e calculado o índice de kappa. Seguiu-se a essa avaliação uma quantificação dos graus de discordâncias obtidos, pela instituição de pesos de 0,2 para cada categoria discordante, permitindo, assim, o cálculo do kappa ponderado.
O observador A mostrou alta freqüência de discordâncias entre as duas avaliações realizadas, ocasionando um indice de kappa bastante baixo $(0,078)$. Quando se instituíram os pesos de 0,2 para cada grau de discordância, o valor obtido com a análise de kappa apresentou elevação de $7,8 \%$ para $16,6 \%$, representado pelo índice de kappa ponderado.

O observador B foi o que apresentou o maior indice de concordância. Pôde-se perceber um único diagnóstico de lesão de alto grau (HiSIL) em cada uma das análises feitas por ele, secundário à análise da mesma lâmina. O valor de kappa encontrado foi de 0,7447 e encontrase bastante próximo do ponto de corte máximo de $75 \%$ do índice de kappa, o que indica boa correlação na concordância obtida. Após a instituição de pesos de 0,2 para cada grau de discordância, esse observador ultrapassou esse ponto de corte, indicando excelente índice de concordância.

O observador $\mathrm{C}$ destacou-se dos demais pela maior freqüência de resultados normais em suas duas análises. Pôde-se observar, também, a ausência de resultados sugestivos de lesões de alto grau (HiSIL) e menor freqüência de alterações inflamatórias em seus laudos. A análise feita pelo indice de kappa revelou, também para esse citopatologista, bom grau de concordância entre laudos $(0,521)$. Como ocorreu com as análises já mencionadas, quando foi instituído um peso para cada grau de discordância, houve elevação do índice de kappa. Essa observação também foi válida nas duas análises feitas pelo observador C. As análises feitas por esse observador também se destacaram pela ausência de diagnósticos de lesões de alto grau e número maior de resultados normais, se comparado aos outros observadores.

As avaliações realizadas pelo observador D indicaram fraco grau de concordância, com um valor de kappa inferior a 40\% $(0,388)$. Após a instituição do peso de 0,2 para cada grau de discordância encontrado, observou-se importante elevação no índice de concordância de kappa, que adquiriu o valor de 0,55.

Houve discordância entre diferentes patologistas em relação à avaliação de lâminas previamente diagnosticadas como ASCUS, o mesmo ocorrendo quando duas avaliações independentes foram realizadas por um mesmo patologista.

$\mathrm{Na}$ amostra desta casuística, foram formulados 16 diagnósticos de atipias glandulares de significado indeterminado (AGUS) dentre os 400 laudos feitos. 


\section{Discussão}

Surgido no final de 1988, o Sistema de Bethesda tem substituído a antiga classificação de Papanicolaou na análise do esfregaço cervical nos Estados Unidos da América e em grande parte do mundo ${ }^{13}$. Esse sistema de classificação é binário, dividindo as categorias em dois grupos: lesões intra-epiteliais de baixo grau (LoSIL) e lesões intra-epiteliais de alto grau (HiSIL). Um terceiro grupo foi instituído, a categoria das atipias escamosas de significado indeterminado (ASCUS). Este estudo teve a intenção de analisar a possibilidade de existência de subjetividade na avaliação dessa categoria por meio de comparações entre laudos de lâminas previamente classificadas como ASCUS. Essa análise foi feita comparando-se um mesmo observador e observadores distintos. Foi, também, analisado o grau de discordância existente. Para tanto, foi utilizado o teste de kappa e sua variação pontual, o kappa ponderado.

O método de kappa é amplamente difundido e utilizado quando se deseja observar o grau de concordância em determinado assunto. Usualmente, os valores superiores a 0,75 são interpretados como indicativo de excelente concordância. Valores inferiores a 0,40 indicam concordância ruim e os intermediários destes valores são considerados razoáveis. O kappa ponderado é utilizado na quantificação da magnitude relativa da discordância. É realizado colocando-se pesos em cada grau de discordância. A interpretação da magnitude do kappa ponderado é a mesma usada em sua versão simples ${ }^{14}$.

Nessa revisão da literatura, não foi encontrado outro estudo que analisasse comparativamente laudos de um mesmo citopatologista sobre uma mesma lâmina previamente diagnosticada como ASCUS. Essa avaliação, ao que parece, tem grande importância, pois somente ela tem o poder de demonstrar a existência de um grau de subjetividade nas avaliações desses diagnósticos. Quando é feita análise comparativa entre laudos de citopatologistas distintos, não é avaliada a presença ou não da subjetividade implícita, mas a existência de interpretações diferentes de determinados achados. Quando, porém, um mesmo citopatologista emite laudos diferentes para uma mesma lâmina analisada em momentos distintos, significa a clara existência de um grau de subjetividade em sua análise.

Dentre as 400 análises feitas pelos quatro citopatologistas nas duas avaliações, a qualidade dos esfregaços mostrou-se inadequada (ressecada) em somente 11. Essas lâminas não foram desconsideradas neste estudo, pois não houve unanimidade para nenhuma delas quanto ao impedimento de leitura (somente nesse caso é que elas seriam enquadradas dentro dos critérios de exclusão).

Entre os quatro citopatologistas participantes, houve $7,7 \%$ de concordância de diagnósticos entre os dois laudos formulados pelo citopatologista A e $74,4 \%$ nas análises do observador $\mathrm{B}$, passando por 52,1 e $38,8 \%$ dos observadores $C$ e $\mathrm{D}$, respectivamente. A análise feita pelo método de kappa, já descrita, indica que existe concordância satisfatória quando os valores se situam entre 40 e $75 \%$, valores estes somente alcançados por dois dos quatro participantes. Esses números encontrados após a análise pelo método de kappa representam a evidente ausência de critérios precisos utilizados pelos citopatologistas nas avaliações de lâminas de colpocitologias oncóticas por meio da classificação de Bethesda, em sua revisão feita em $1991^{5}$. Deve-se salientar, ainda, que essas análises comparativas internas (entre um mesmo observador) foram realizadas entre citopatologistas que estavam cientes, previamente às avaliações, da metodologia que seria utilizada neste estudo. Nas análises de lâminas realizadas dentro dos programas de rastreamento, apenas $10 \%$ são feitas por citopatologistas e a imensa maioria é realizada por citotécnicos, que teoricamente possuem menor capacitação técnica para a diferenciação dos laudos.

$\mathrm{Na}$ amostra desta casuística, foram formulados 16 diagnósticos de atipias glandulares de significado indeterminado (AGUS) dentre os 400 laudos feitos. O diagnóstico de AGUS é bom parâmetro da qualidade dos laudos fornecidos por um laboratório, sendo que sua freqüência deve variar entre 0,2 e 0,7, mas não deve ultrapassar $1 \%{ }^{15}$.

Foi observada discrepância em relação a diagnósticos de AGUS. Esses laudos só estiveram presentes nas análises realizadas pelos citopatologistas A e B em sete e pelo observador $\mathrm{C}$ em dois dos 100 laudos fornecidos, respectivamente. Em apenas uma dentre todas as lâminas examinadas houve concordância desse diagnóstico por dois dos quatro citopatologistas, demonstrando, também, ausência de critérios citopatológicos bem definidos para esse importante achado. Esse diagnóstico não foi feito em uma mesma lâmina pelo observador A, sendo repetido em apenas duas lâminas nas observações feitas pelo observador B.

A Organização Mundial de Saúde (OMS) estimou 300.000 casos novos de câncer do colo 
uterino para o ano de 2002 em todo o mundo. Desses, esperava-se que cerca de $70 \%$ ocorressem em países subdesenvolvidos ou em desenvolvimento ${ }^{16}$. Diante desses números alarmantes, pôde-se concluir que o exame de rastreio do câncer cervical deve ter alta sensibilidade, como qualquer exame que se destine ao rastreamento, mas não pode se privar de especificidade elevada. Isto significa que é necessário que os resultados falso-positivos sejam reduzidos ao mínimo. No presente estudo, nenhum caso de carcinoma invasor foi suspeitado em todas as análises feitas, indicando não ser necessária a realização de propedêuticas complementares nos casos de um diagnóstico de ASCUS em um esfregaço cervical. Outra conduta seria a realização de nova coleta e análise, visto que alguns dos laudos fornecidos eram relativos à presença de lesões de alto grau (HiSIL) ou a atipias glandulares de significado indeterminado (AGUS). Essa conduta não tem sido a adotada pela maioria dos programas de prevenção, pois acarreta elevação substancial dos custos do programa sem melhoria na sobrevida global dessas pacientes.

O grande percentual de exames cujos diagnósticos passaram de significado indeterminado a sugestivos de inflamatórios, com 45 e $51 \%$ na primeira e segunda avaliação, respectivamente, leva a concluir sobre a necessidade de serem abordadas as causas das cervicites previamente à coleta do esfregaço.

Ponto interessante de ser analisado encontra-se na divergência encontrada na avaliação comparativa intercitopatologistas. Quando foram analisados todos os laudos das duas avaliações em conjunto, encontrou-se grau de concordância de $50,6 \%$ pelo método de kappa. Esse resultado demonstrou a existência de discordâncias entre os laudos de lâminas diagnosticadas como ASCUS e que essas divergências enquadraram-se aos valores de padrões de boa correlação pelo método de kappa.

Este estudo vem contribuir com os demais existentes na literatura. Desde a criação da classificação de Bethesda, em $1988^{3}$, a categoria composta pelos achados citopatológicos sugestivos de ASCUS é a que mais tem levado a discussões e indagações sobre sua reprodutibilidade e seu valor clínico. Logo após a sua criação, movimentos surgiram por parte dos ginecologistas clinicos sobre qual a conduta adequada a ser instituída e o seu por quê, visto que estava ocorrendo verdadeiro abuso na utilização dessa categoria pelos citopatologistas. Para tanto, foi organizada nova reunião, também na cidade de Bethesda, em 19915. Desta seguiu-se a neces- sidade de especificação dos achados na categoria de ASCUS, relatando o termo "favorável" a após o seu uso. Este estudo pautou-se na especificação proposta nesse segundo encontro em Bethesda, com a intenção de analisar sua eficácia na prática clínica. Constatou-se, pelos resultados deste trabalho, a existência de um grau de subjetividade nas avaliações pelos citopatologistas, resultado este indicativo da necessidade de realização de mudanças nesse item da classificação de Bethesda, revisão de $1991^{5}$. Deve-se lembrar, ainda, que eles estavam cientes da metodologia utilizada e que $90 \%$ dos laudos fornecidos nas avaliações de lâminas de colpocitologias oncóticas na prática clínica são fornecidos por citotécnicos.

Uma terceira reunião na cidade de Bethesda ocorreu no ano de $2001^{13}$, após o início deste estudo. A categoria de ASCUS foi novamente modificada, passando a ser denominada de ASC (células escamosas atípicas) e tendo importância clínica apenas quando seguida da letra $\mathrm{H}$, indicativa de suspeita de lesão de alto grau. Essa alteração instituída na categoria de ASCUS na última revisão da classificação de Bethesda reforça as conclusões obtidas durante as análises dos resultados deste estudo. Esta revisão objetivou a valorização dos resultados cuja atipia indeterminada pudesse estar associada a achados compativeis com lesões de alto grau, por seu risco potencial de invasão em periodo inferior a um ano, intervalo indicado e usado nos programas de rastreio do câncer do colo uterino. Em todas as demais especificações da categoria de ASCUS, introduzidas durante a primeira revisão de Bethesda, permaneceu a indicação de acompanhamento da paciente seguindo-se as orientações habituais do programa de rastreio.

\section{ABSTRACT}

Objective: to evaluate the existence of intra and intercytophathologists disagreement in the analysis of cervical slides previously diagnosed as atypical skin cells with undetermined significance (ASCUS), and the degree of this disagreement.

Methods: a transversal study of 50 cervical slides of Pap smears previously diagnosed as ASCUS, collected in November 2000 in Contagem town. They were analyzed and classified by four cytopathologists according to the first Bethesda system review of 1991 (normal, atrophic alteration, inflammatory alteration, suggestive of LoSIL, suggestive of HiSIL, suggestive of invasive carcinoma and others). After the first analysis, the slides were 
renumbered in a random order and sent to the same cytophathologists for a new exam. The Kappa test and the weighted Kappa were used in the analysis of the results.

Results: there was a high degree of disagreement between the different analyses of the same cytopathologist, varying from 7.8 to $74.4 \%$ according to the Kappa test. When a weight of $20 \%$ was settled for each degree of disagreement, these values increased from $16.1 \%$ for the cytopathologist $A$ to $81.08 \%$ for the cytopathologist $B$. Concerning the comparative analyses made by different examiners the Kappa test values obtained varied from $50.6 \%$ to $63.4 \%$ in the normal and weighted versions, respectively.

Conclusions: this study confirms the existence of subjectivity in the analysis of the ASCUS category and imprecision in the analysis criteria by the same examiner.

KEY WORDS: ASCUS. Cytopathology.Cancer screening. Cervix: intraepithelial neoplasia.

\section{Referências}

1. National Institutes of Health. Cervical cancer: NIH consensus statement. Bethesda: National Institutes of Health; 1996.

2. Nieminen P, Kallio M, Hakama M. The effect of mass screening on incidence and mortality of squamous and adenocarcinoma of cervix uteri. Obstet Gynecol 1995; 85:1017-21.

3. National Cancer Institute Workshop. The 1988 Bethesda System for reporting cervical/vaginal cytologic diagnoses. Bethesda: National Institutes of Health; 1989.

4. Kurman RJ, Solomon D. The Bethesda system for reporting cervico/vaginal cytologic diagnoses: definitions, criteria, and explanatory notes for terminology and specimen adequacy. $1^{\text {st }}$ ed. New York: Springer-Velarg; 1993.

5. Kurman RJ, Malkasian GD Jr, Sedlis A, Solomon D. From Papanicolaou to Bethesda: the rationale for a new cervical cytologic classification. Obstet Gynecol $1991 ; 77: 779-82$.
6. Davey DD, Naryshkin S, Nielsen ML, Kline TS. Atypical squamous cells of undetermined significance: interlaboratory comparison and quality assurance monitors. Diagn Cytopathol 1994; 11:390-6.

7. Ferris DG, Wright TC Jr, Litaker MS, et al. Triage of women with ASCUS and LSIL on Pap smear reports: management by repeat Pap smear, HPV DNA testing, or colposcopy? J Fam Pract 1998; 46:125-34.

8. Cox JT, Lorincz AT, Schiffman MH, Sherman ME, Cullen A, Kurman RJ. Human papillomavirus testing by hybrid capture appears to be useful in triaging women with a cytologic diagnosis of atypical squamous cells of undetermined significance. Am J Obstet Gynecol 1995; 172:946-54.

9. Slawson DC, Bennett JH, Herman JM. Follow-up Papanicolaou smear for cervical atypia: are we missing significant disease? J Fam Pract 1993; 36:289-93.

10.Kinney WK, Manos MM, Hurley LB, Ransley JE. Where's the high-grade cervical neoplasia? The importance of minimally abnormal Papanicolaou diagnoses. Obstet Gynecol 1998; 91:973-6.

11.Kurman RJ, Solomon D. The Bethesda System for reporting cervical/vaginal cytologic diagnoses. $2^{\text {nd }}$ ed. New York: Springer Verlag; 1994. p.30-43.

12.Gordis L. Assessing the efficacy of preventive and therapeutic measures: randomized trials. Epidemiology. $2^{\text {nd }}$ ed. Philadelphia: W. B. Saunders; 2000.

13.Bollmann R, Bollmann M, Henson DE, Bodo M. DNA cytometry confirms the utility of the Bethesda system for the classification of Papanicolaou smears. Cancer 2001; 93:222-8.

14.Cohen J. Weighted kappa. Nominal scale agreement provision for scaled disagreement or partial credit. Psychol Bull 1968; 70:213-20.

15.Kaferle JE, Malouin JM. Evaluation and management of AGUS Papanicolaou smear. Am Fam Physician 2001; 63:2239-44.

16.Garcia AA, Bi J. Cervical cancer. 2002 Apr [cited 2002 Out]. Available from: http://www.emedicine.com/ med/topic324.htm. 